Article

\title{
Retaining Members of Community Supported Agriculture (CSA) in California for Economic Sustainability: What Characteristics Affect Retention Rates?
}

\author{
Ryan E. Galt ${ }^{1, *}$, Julia Van Soelen Kim ${ }^{2}$, Kate Munden-Dixon ${ }^{3}$, Libby O. Christensen ${ }^{4}$ and \\ Katharine Bradley ${ }^{5}$ \\ 1 Department of Human Ecology, University of California, Davis, CA 95616, USA \\ 2 UC Cooperative Extension, Novato, CA 94947, USA; jvansoelen@ucanr.edu \\ 3 Geography Graduate Group, University of California, Davis, CA 95616, USA; kmundendixon@ucdavis.edu \\ 4 Colorado State University Extension, Steamboat Springs, CO 80477, USA; lchristensen@co.routt.co.us \\ 5 Independent Scholar, New York, NY 11205, USA; katiefranbradley@gmail.com \\ * Correspondence: regalt@ucdavis.edu
}

Received: 27 February 2019; Accepted: 22 April 2019; Published: 28 April 2019

check for updates

\begin{abstract}
Community supported agriculture (CSA) is one response to major ecological and social problems in the conventional agrifood system. Here we are concerned with how CSA management can enhance the economic sustainability of CSAs. More specifically, using a survey of 111 CSA farms in California, we analyze how specific variables in five domains-CSA management characteristics, farmer characteristics, farm characteristics, economic characteristics, and region-influence retention rates (the proportion of CSA members continuing from one year to the next). Our analysis involves first conducting bivariate correlations, then building a simple causal model that theorizes the direction of causation, then constructing a series of ordinary least squares (OLS) multiple regression models to hold constant independent variables. Our discussion draws out recommendations from our findings for CSA farmers and organizations that support CSA, including increasing the length of the season, increasing crop type diversity, including fruit in standard shares, bringing farming practices into line with organic standards, working with other CSAs to reduce inter-CSA competition, and changing marketing regions for farms in certain regions that appear to be highly saturated. We conclude by identifying more collective routes that CSAs can take to cultivate "CSA people" for a more sustainable economic dimension of CSAs in the long term.
\end{abstract}

Keywords: community supported agriculture (CSA); economic sustainability; retention rates; competition; CSA management

\section{Introduction}

Community supported agriculture (CSA) is one response to major ecological and social problems in the conventional agrifood system. By depending on largely renewable agricultural inputs and shortening the supply chain greatly, most CSAs attempt to enhance the ecological sustainability of the agrifood system by socially-embedding production and consumption [1-3]. To do so, CSAs rely on dedicated members who generally pay ahead of season for shares of the farm's production. CSA has grown considerably in recent decades in the USA, from a handful of farms in the 1980s to many thousands [4].

A recent large survey of Midwestern farmers practicing direct marketing has shown that farms with CSAs are practicing the most ecologically sustainable form of agriculture [3]. While this strong 
ecological commitment exists amongst CSA farmers in other places [5] and, therefore, appears to be an essential characteristic of CSA, the sustainability of the economic dimension of CSA faces serious challenges. Many CSA farmers earn very low salaries [6], often comparable to farmworkers, which brings into question how long many can continue [7]. Thus, while enhancing environmental quality, CSA farmers often engage in self-exploitation, which suggests that the three dimensions of sustainability as commonly conceived —environmental, economic, and social [8] —are not balanced within CSA. Additionally, a number of processes continue to undermine the economic dimension. Recent research suggests that increased competition in CSA and other direct marketing channels, and with non-CSA outlets, including grocery store and food delivery services that increasingly emphasize their sourcing of local food products, is undercutting CSA farmer well-being and some aspects of the social embeddedness of CSAs [9]. An important question is how managers of CSAs can respond, individually and collectively, to these challenges and enhance the economic sustainability of CSA.

A core part of economic well-being for CSA farmers is the issue of retaining members from season to season [10]. As Galt et al. [11] (p. 172) note, "[m]any of CSA's benefits to farmers-knowing the size of demand, potentially reducing the effort needed to sell one's produce compared to other market channels, and having a loyal customer base-require high retention rates." As mainstream market outlets continue to emphasize their localness and create convenient CSA-like boxes (without being farm based, and without the ecological commitments of CSA farms), a crucial concern among CSA farmers is maintaining their memberships [11].

The economic dimension of CSA sustainability, closely tied to retention of CSA members, has received relatively little academic attention, especially concerning the question of whether specific CSA management decisions can impact member retention. Specifically, in our conversations with CSA farmers, they have often wondered whether specific changes to their management practices-for example, shortening the payment period, adding certain produce and customizing shares-would impact member retention. In this paper, we analyze a large-scale dataset from a survey of 111 CSAs in California to answer this important question: Which CSA characteristics influence member retention rates, and in what ways?

The paper is organized as follows. We first review the literature on CSA retention rates. We then explain our CSA farmer survey, with details about how we requested information on retention rates. We then present our findings, focusing first on bivariate correlations between specific characteristics and retention rates, and then creating a synthesis from political economic theory and a multiple regression model. Our discussion draws out recommendations from our findings for CSA farmers and organizations that support CSA, including increasing the length of the season, increasing crop type diversity, including fruit in standard shares, bringing farming practices into line with organic standards, working with other CSAs to reduce inter-CSA competition, and changing marketing regions for farms in certain regions that appear to be highly saturated. We conclude by identifying more collective routes that CSAs can take to cultivate "CSA people" for a more sustainable economic dimension of CSAs in the long term.

\section{Prior Analyses of CSA Retention Rates}

Most of the academic literature on retention in CSAs focuses on perspectives of former CSA members. These studies rely on surveys of and interviews with former members to understand why they left [11-19]. This literature has consistently shown that "former members leave mainly due to dissatisfaction with the share, especially its variety and/or their ability to customize it to their needs" [11] (p. 174).

A handful of academic studies mention CSA retention rates, but very few attempt to explain them. Retention rates are usually reported briefly, and different methods are used. One method is to ask members. Kane and Lohr [12] (p. 35) asked members of seven farms at the end of the season whether they would join again, and found that $63.7 \%$ would. Landis et al. [20] (p. 78) asked a similar question 
and report a $68 \%$ intention to renew, while Lang [21] (p. 19) reported a $75 \%$ affirmative response to a similar question. The other method is to ask farmers. Perez et al. [14] (p. 3) note that the CSA farmers in their study averaged retention rates of $65 \%$. Three collaborative CSAs studied by Flora and Bregendahl [18] (p. 341) had retention rates of $80 \%, 69 \%$ and $59 \%$. Another method is detailed tracking of membership based on unique identifiers: Small Farm Central, a company that created a technology platform to facilitate customer service for farms with CSAs/farm share programs, reported an average CSA retention rate of $46.1 \%$ in 2015 [22] and 45.2\% in 2014 [23]. Their method tracked member retention using specific email address, likely resulting in lower estimates since some members undoubtedly use different email addresses at different points in the year, and these would be counted as leaving.

Only three sources explore CSA retention rates in any depth. One article by CSA farmers Docter and Hildebrand [24] (p. 1) in the trade magazine Growing for Market notes that CSA farms in their first few years tend to have lower retention rates, suggesting that $50 \%$ is normal. In studies of young CSAs, this appears to be true: Cicero [25] (p. 65) reported "the turnover rate at the Philadelphia Community Farm in Wisconsin was approximately 50\% during its formative years" and Goland [13] (p. 20) noted a $33 \%$ retention rate for the case study of a CSA in its early years. Docter and Hildebrand [24] (p. 1) also note that a retention rate of "successful" CSAs is $75 \%$ to $80 \%$ (a figure cited by $[15,16]$ ).

Two studies used data from multiple CSA farms to examine the relationship between retention rates and other variables about the farm, the farmer, and the CSA [11,26]. In the first, Tegtmeier and Duffy [26] researched 55 Midwestern CSAs and reported only one statistical relationship with retention-farmers' feeling of being paid a fair wage was positively correlated with retention-and they therefore note that increasing member retention will likely increase financial returns. In the latest study, Galt et al. [11], using data from 80 CSAs in California, examined whether share customization-a strategy to retain more members suggested by most studies of former members-increases retention rates, and found that it does not. Although former members stated they left their CSAs largely for reasons having to do with lack of choice-many former members left because the product mix did not meet their needs, they lacked choice about the products included, and there was too little diversity of products-the authors found no differences in retention rates between CSAs offering customization and those with a standard share [11]. They call this finding the "CSA customization paradox" since their data and other studies of former members suggest that share customization should result in greater member retention, but it does not in their data.

Overall, the review above shows that only two relationships between retention rates and CSA characteristics-farmers' perception of fair wages and share customization-have been explored and reported in the academic literature. Much remains to be gained by further analysis of the various characteristics that influence retention rates. Below we conduct this analysis to help guide farmers toward effective strategies for enhancing the economic sustainability of CSAs.

\section{Methods}

Here we use data from a statewide, online survey of Californian CSA farmers (As a note, a few of the survey respondents are not farmers, but rather the managers of the CSA, hired by the farmers. Additionally, some are coordinators of multi-farm CSAs, rather than farmers. However, for ease of presentation, we refer to the respondents of the CSA farmer survey as farmers.) To determine the survey population, we made a list of all CSAs in the state using internet databases, then verified that each was in operation (for more, see [4,9]). We gathered responses for the CSA farmer survey from July 2013 to January 2014, resulting in 103 responses from existing CSAs and 8 responses from recently discontinued CSAs (an additional 34 CSA farmers responded, but we included only those responses answering more than half of the survey questions), for a total of 111 responses from a population that we determined to be 244 in size (for population size calculations, see [9] (pp. 496-497).

Of the 111 responses, 80 had usable data on retention rates. We calculated retention rates in two different ways (Options A and B, detailed below) as recommended by our advisory panel of 
CSA farmers and advocates. First, farmers were asked if they had specific counts of members over various time periods. If they responded "yes," the survey moved them to Option A, which included questions about specific member numbers: (1) The number of continuing members in January 2013, compared to January 2012; (2) the number of discontinued member over the same time period; and (3) the number of new members over the same time period. If farmers responded that they did not have specific counts, they skipped to Option B, where they were asked to "Please estimate your retention rate (as a percentage of all your members) and explain how you conceptualize or calculate retention." Respondents who completed Option A questions also had the chance to respond to the Option B question.

Using these two options, we worked to calculate a best estimate of retention rates using a multi-step process. First, retention rates from Option A were calculated by taking the numerator as (\#1) the number of members who continued in 2012 and dividing it by a denominator created by adding (\#1 [continuing members]) plus (\#2) discontinuing members (the denominator was also checked against the reported number of members they had at the start of 2012). Option A's average for 2012 retention rates was $66.3 \%(n=55)$, while for 2013 it was $57.2 \%(n=56)$. Second, we read the responses to Option B's open-ended responses, and calculated them as a percentage retention rate. In some cases, farmers reported turnover or attrition rates (the inverse of retention), and these were converted into retention rate. Option B's average retention rate for 2012-2013 was 61.7\% $(n=75)$, almost precisely in the middle of the two averages for Option A. Third, if respondents completed both Option A and Option B (true for 46 farmers), the responses were compared, with Option A being generally preferred due to its greater precision in how it was calculated, except in cases where Option A's data seemed suspect (e.g., there were large differences in those numbers relative to member numbers in 2012 reported elsewhere by the respondent). In this way, checks were made to generate a best estimate of retention rate for each farm by considering both Option A and Option B. This combined best estimate of retention rate had an average of $62.9 \%(n=80)$.

Our sample of 80 is larger than any previous published academic study of CSA retention rates, as the only previous research that examined relationships between retention rates and other variables was done in the Midwest with data from 55 CSAs [26]. This means that we have the possibility of uncovering new statistical relationships based on a larger sample size and the breadth of the CSA farmer survey.

To understand what characteristics of CSAs influence retention rate, or are influenced by it, we ran Pearson's and Spearman's bivariate correlations (depending on the variable type) between retention rate and 139 variables from the survey. For reporting below, we group these into five domains: CSA management, farmer characteristics, farm characteristics, economics, and region. We focus on significance at the $5 \%$ level, but also consider significance at the $10 \%$ level. We then present a multiple regression analysis to determine the strength of the relationships while holding constant the other variables.

\section{Findings}

Retention rates vary substantially between the 80 CSAs. The mean retention rate was $62.9 \%$. The mean plus one standard deviation was $84 \%$, while the mean minus one standard deviation was $41.7 \%$. The median was $62.7 \%$. The highest retention rate was $100 \%(n=4)$, while the lowest was $0 \%$ $(n=1)$.

CSAs in California are, on average, losing $37.1 \%$ of their members annually. Only $40 \%$ of the CSAs were above the cutoff for success (75\% retention rate) mentioned by Docter and Hildebrand [24]. Docter and Hildebrand [24] applied this guideline to CSAs in their fifth or sixth seasons; restricting our sample to CSAs five-years old and older, the mean retention rate was $64.7 \%$, and $43.5 \%$ of these CSAs have retention rates above $75 \%$. Thus, most CSAs in California-new and mature-are struggling with retention, which has important implications for the overall economic sustainability of their operations. While some CSA operations may be able to reach and maintain an appropriate number of 
members, the costs associated with adding additional members each year is high, requiring energy, time, and money.

We examined retention rates regionally by breaking the state into cultural and biophysical regions. Our regionalization draws upon that of Guthman [27] in her study of organic agriculture in California, with minor changes. Since we created our regions with whole counties, the minor differences are that we included Sacramento County in our Delta/East Bay region (rather than splitting it between North Valley and East Valley), and we combined Guthman's East Valley and West Valley into our San Joaquin Valley region. Retention rates vary considerably by region (Table 1). The Central Coast had the highest average retention rate $(75.5 \%)$, significantly higher than the other regions, while the Sacramento Valley had the lowest average retention rate of $53.4 \%$.

Table 1. Retention rates by region of farm.

\begin{tabular}{ccccc}
\hline & Retention Rate (\%) & \multicolumn{3}{c}{$\boldsymbol{t}^{\text {-Tests }}{ }^{\wedge}$} \\
\cline { 3 - 5 } & & $\boldsymbol{n}$ & $\boldsymbol{t}$ & $\boldsymbol{p}$-Value $\boldsymbol{~}$ \\
\hline Far North $^{1}$ & 64.0 & 4 & -0.10 & 0.46 \\
Cascades/Sierra Nevada $^{2}$ & 64.4 & 5 & -0.16 & 0.44 \\
Sacramento Valley $^{3}$ & 53.4 & 7 & 1.22 & 0.11 \\
North Coast $^{4}$ & 63.1 & 15 & -0.06 & 0.48 \\
Delta/East Bay $^{5}$ & 57.3 & 16 & 1.16 & 0.13 \\
Central Coast $^{6}$ & 75.5 & 8 & -1.74 & 0.04 \\
San Joaquin Valley $^{7}$ & 58.8 & 5 & 0.44 & 0.33 \\
South Coast $^{8}$ & 71.3 & 9 & -1.23 & 0.11 \\
Desert Valleys $^{9}$ & 67.5 & 4 & -0.43 & 0.34 \\
Southwest $^{10}$ & 58.3 & 7 & 0.59 & 0.28 \\
California & 62.9 & 80 & &
\end{tabular}

^ one-tailed $t$-tests of the CSA farms' retention rates in one region compared to the those in all other regions. t significance here is highlighted as follows: $\leq 0.05$ and $>0.01=* * .{ }^{1}$ Del Norte, Humboldt, Shasta, Siskiyou, and Trinity Counties. ${ }^{2}$ Alpine, Amador, Calaveras, El Dorado, Inyo, Lassen, Modoc, Mono, Nevada, Placer, Plumas, Sierra, and Tuolumne Counties. ${ }^{3}$ Butte, Colusa, Glenn, Sutter, Tehama, and Yuba Counties. ${ }^{4}$ Lake, Marin, Mendocino, Napa, and Sonoma Counties. ${ }^{5}$ Alameda, Contra Costa, Sacramento, Solano, and Yolo Counties.

${ }^{7}$ Fresno, Kern, Kings, Madera, Mariposa, Merced, San Joaquin, Stanislaus, and Tulare Counties. ${ }^{8}$ San Luis Obispo, Santa Barbara, and Ventura Counties. ${ }^{9}$ Imperial, Riverside, and San Bernardino Counties. ${ }^{10}$ Los Angeles, Orange, and San Diego Counties.

\subsection{CSA Management Variables: Correlations}

CSA farmers often consider whether certain ways of managing their CSA (e.g., changing delivery frequencies, shortening payment periods, customizing boxes) would result in different retention rates. We found very few significant relationships between the 34 specific CSA management choices and CSA retention rates (Table 2). Indeed, only five were significant at the $5 \%$ level but for many of the variables the absence of significance is significant. We organized the 34 variables into six categories: Share price and payment variables, share configuration variables, share content variables, pickup/delivery variables, member-farm relationship variables, and member number and population variables. 
Table 2. Correlations of community supported agriculture (CSA) management variables with member retention.

\begin{tabular}{|c|c|c|c|c|c|c|c|}
\hline & \multicolumn{3}{|c|}{ Variable Descriptors } & \multicolumn{4}{|c|}{$\begin{array}{l}\text { Correlation with Member } \\
\text { Retention }\end{array}$} \\
\hline & Variable Type & Mean & St. Dev. & $\begin{array}{l}\text { Coefficient } \\
(r \text { or } r h o)^{\wedge}\end{array}$ & $p$-Val & & $n$ \\
\hline \multicolumn{8}{|l|}{ Share price and payment variables } \\
\hline Share price & continuous & $\$ 25.26$ & $\$ 8.76$ & -0.07 & 0.28 & & 73 \\
\hline Minimum payment period ${ }^{1}$ & ordinal & 4.7 & 2.7 & 0.07 & 0.29 & & 66 \\
\hline $\begin{array}{l}\text { Difference between share price and average CSA price in primary } \\
\text { market region }\end{array}$ & continuous & $-\$ 2.07$ & $\$ 7.72$ & -0.03 & 0.41 & & 65 \\
\hline \multicolumn{8}{|l|}{ Share configuration variables } \\
\hline Availability (months per year) & continuous & 8.8 & 2.7 & 0.20 & 0.05 & * & 68 \\
\hline Item quantity reflects seasons of abundance and scarcity & binary & 0.55 & 0.50 & 0.03 & 0.40 & & 76 \\
\hline The value of the share is consistent from week to week, season to season & binary & 0.64 & 0.48 & -0.01 & 0.47 & & 76 \\
\hline Multiple box sizes are available (e.g., full share, half share) & binary & 0.37 & 0.49 & -0.11 & 0.17 & & 76 \\
\hline $\begin{array}{l}\text { Various delivery frequencies available (e.g., each week, every other } \\
\text { week, etc.) }\end{array}$ & binary & 0.38 & 0.49 & -0.25 & 0.01 & $* * *$ & 76 \\
\hline $\begin{array}{l}\text { Shares are customizable in terms of items (i.e., members can } \\
\text { choose items) }\end{array}$ & binary & 0.16 & 0.37 & -0.07 & 0.27 & & 76 \\
\hline Regular add-ons available for an extra fee (e.g., added fruit share) & binary & 0.38 & 0.49 & -0.08 & 0.25 & & 76 \\
\hline \multicolumn{8}{|l|}{ Share content variables } \\
\hline Vegetables from the CSA farm included & ordinal $^{2}$ & 3.4 & 1.2 & -0.06 & 0.62 & & 76 \\
\hline Fruit from the CSA farm included & ordinal $^{2}$ & 2.0 & 1.5 & 0.28 & 0.01 & $* * *$ & 76 \\
\hline Meat from the CSA farm included & ordinal $^{2}$ & 0.3 & 1.0 & 0.05 & 0.68 & & 76 \\
\hline Eggs from the CSA farm included & ordinal $^{2}$ & 1.1 & 1.7 & -0.09 & 0.43 & & 76 \\
\hline Grain from the CSA farm included & ordinal $^{2}$ & 0.2 & 0.6 & -0.04 & 0.76 & & 76 \\
\hline Flowers from the CSA farm always included & binary & 0.1 & 0.4 & 0.20 & 0.09 & $\circ$ & 76 \\
\hline Prepared foods from the CSA farm included & ordinal $^{2}$ & 1.0 & 1.5 & 0.08 & 0.48 & & 76 \\
\hline \multicolumn{8}{|l|}{ Pickup/delivery variables } \\
\hline Shares regularly delivered to drop-off locations & binary & 0.66 & 0.48 & 0.07 & 0.27 & & 76 \\
\hline Shares regularly delivered to individual houses & binary & 0.30 & 0.46 & -0.13 & 0.13 & & 76 \\
\hline Shares are picked up on farm & binary & 0.58 & 0.50 & -0.05 & 0.33 & & 76 \\
\hline \multicolumn{8}{|l|}{ Member-farm relationship variables } \\
\hline The farm shares production risk with members & Likert $^{3}$ & 2.3 & 1.2 & -0.05 & 0.64 & & 76 \\
\hline Members form a supportive community around the farm & Likert $^{3}$ & 3.3 & 0.9 & 0.17 & 0.14 & & 77 \\
\hline Members get a good value for their money & Likert $^{3}$ & 4.5 & 0.7 & 0.24 & 0.04 & $* *$ & 77 \\
\hline $\begin{array}{l}\begin{array}{l}\text { Member payments cover the costs of production for the CSA, incl. } \\
\text { farmer earnings }\end{array}\end{array}$ & Likert $^{3}$ & 3.2 & 1.2 & 0.15 & 0.20 & & 77 \\
\hline Farm hosts events related to our CSA & binary & 0.58 & 0.50 & -0.04 & 0.37 & & 73 \\
\hline Members pre-pay in advance for shares & binary & 0.89 & 0.31 & 0.01 & 0.47 & & 73 \\
\hline A core group of members helps with production decisions & binary & 0.03 & 0.16 & 0.22 & 0.03 & $* *$ & 73 \\
\hline A core group of members helps with CSA share distribution & binary & 0.08 & 0.28 & -0.04 & 0.37 & & 73 \\
\hline \multicolumn{8}{|l|}{ Member number and population variables } \\
\hline Numbers of members, 2013 & continuous & 151 & 315 & -0.04 & 0.36 & & 78 \\
\hline Farmer wants more members & binary & 0.70 & 0.46 & -0.07 & 0.27 & & 79 \\
\hline Population in primary market region & continuous & 143,753 & 205,292 & -0.13 & 0.14 & & 69 \\
\hline Population per CSA in primary market region (s) & continuous & 160,528 & 202,247 & -0.17 & 0.08 & $\circ$ & 69 \\
\hline
\end{tabular}

^ two different correlation coefficients are shown, depending on the appropriate correlation test: (1) Pearson's $r$ coefficient, between retention rate and continuous (including count, count index, index, percentage, and year) and binary variable types; and (2) Spearman's rho coefficient, between retention rate and ordinal (including Likert and Likert index) variable types. + significance here is highlighted as follows: $\leq 0.10$ and $>0.05={ }^{\circ}, 0.05=*, \leq 0.05$ and $>0.01=* *$, and $\leq 0.01=* * * .{ }^{1} 1=$ weekly, $2=$ bi-weekly, $3=3$ weeks, $4=$ monthly, $5=1.5$ months, $6=2$ months, $7=$ quarterly, $8=$ half season, $9=$ full season. ${ }^{2} 4=$ always, $3=$ most of the time, $2=$ sometimes, $1=$ infrequently, $0=$ never. ${ }^{3} 5=$ strongly agree, etc., $1=$ strongly disagree.

For the first variable category, none of the share price and payment variables had a significant correlation with retention rate. For the second variable category, share configuration variables, only two were significant at the 5\% level. Importantly, and as we reported elsewhere [11], the strategy most frequently advocated in the literature-shares are customizable in terms of items-has no effect on retention rates. For the $16 \%$ of customizable CSAs-those that allow their members to configure their share items - retention rates were no different from standard CSAs (those with a standardized box). Customizable CSAs had slightly lower retention rates than standard CSAs (59.4\% compared to $63.2 \%)$, but this was not statistically significant $(t=0.57, p=0.29)$. This is the "CSA customization paradox" mentioned in the literature review, to which we will return in the conclusion. As a note about the comparison, the customizable CSAs were no different in product orientation (vegetables, fruit, and livestock) than standard CSAs. There were no differences between most other variables, including 
membership size, acres farmed, organic certification, crop diversity, and profitability. While most CSA characteristic variables were the same, there are some differences, including customizable CSAs being: Less likely to share risk with their members $(t=1.92, p=0.03)$, lower on an index of classic CSA characteristics $(t=1.71, p=0.05)$, more likely to drop off shares at individual homes $(t=-2.70, p=0.01)$, more likely to offer different share sizes $(t=-2.07, p=0.02)$, and more likely to have various add-ons available $(t=-2.89, p=0.01)$. These findings suggest that customizable CSAs also offer a variety of other modifications that move CSA toward a customer-oriented model (its market orientation and commodity exchange relation) from a farm-customer partnership model (its radical philosophical nature and risk-sharing equity relation) $[7,28]$.

One significant share configuration variable was availability (months per year), which was positively associated with retention, suggesting that growing for more months of the year keeps members invested or at least increases the chances they will continue, although it could also be that higher retention rates help drive farmers' interest in expanding their season. The second significant share configuration variable showed a negative association between various delivery frequencies available and retention. Determining causation here is difficult and further research is needed; it could be that CSAs with lower retention rates have attempted more frequency choices in response to low retention, rather than more frequency choices leading to members leaving. However, it might be an aspect of the "tyranny of choice" that Galt et al. [11] theorize in response to too many options.

For the third variable category, share content, only one variable was significant at the $5 \%$ level. Share content questions asked the frequency of including various categories of foods. Fruit from the CSA farm included was significantly associated with higher retention rates. No other items were significant at the $5 \%$ level, but flowers from the CSA farm always included was significant at the $10 \%$ level. For the fourth variable category, pickup/delivery, none of the variables were significant. It appears as though the various forms of pickup and delivery do not matter much, but it also could be that CSAs have already adapted to the needs of their specific area, so little effect appears.

The fifth variable category, member-farm relationship variables, showed two significant correlations at the 5\% level. CSA farmers' response that members get a good value for their money is moderately correlated with retention. It could be that farmers assess this based partly upon retention rates (and therefore there is endogeneity between the variables), but generally it suggests a connection between what farmers feel is a good value and members' retention. The moderate positive correlation with a core group of members helps with production decisions suggests that a core group-an important part of early CSAs in the USA $[29,30]$ —can strengthen retention rates. This probably occurs through multiple mechanisms, including by providing multiple consumers' perspectives within the management discussions of production decisions.

Finally, for the sixth variable category, member number and population variables, none were significantly correlated with retention at the $5 \%$ level. Larger CSAs do not have a harder time with retention, and population size of the primary market is not related to retention. However, population per CSA in primary market(s), a proxy for regional CSA market saturation, was significant below $10 \%$, and explored in greater detail by Galt et al. [9]. This suggests higher levels of competition reduce retention rates, as discussed in more detail below.

\subsection{Farmer Variables: Correlations}

Table 3 shows correlations between farmer variables and retention rates. Of all of the variables concerning farmer demographics, only one (gender is female) was significant at the $5 \%$ level, and it was negatively correlated with retention rates. Widely-held societal biases of farming as male work [31] might be operating here, making it harder for female CSA farmers. Additionally, the other most significant variable (race is white (Farmer A)), significant at the $6 \%$ level, could reflect similar widely-held biases of farming as a white profession in the USA, including dominant narratives and imagery of white famers engaged in alternative food networks [32]. Due to societal biases and perhaps other 
factors such as lower resource access, women and people of color running CSAs might face additional challenges compared to white males.

Table 3. Correlations of farmer variables with member retention.

\begin{tabular}{|c|c|c|c|c|c|c|c|}
\hline & \multicolumn{3}{|c|}{ Variable Descriptors } & \multicolumn{4}{|c|}{$\begin{array}{c}\text { Correlation with Member } \\
\text { Retention }\end{array}$} \\
\hline & Variable Type & Mean & St. Dev. & $\begin{array}{l}\text { Coefficient } \\
(r \text { or } r h o)^{\wedge}\end{array}$ & $p$-Valu & & $n$ \\
\hline \multicolumn{8}{|l|}{ Farmer demographic variables } \\
\hline Age (Farmer A) & count & 44.9 & 13.1 & 0.09 & 0.24 & & 69 \\
\hline Average farmer age, all farm partners & continuous & 46.0 & 12.5 & -0.01 & 0.48 & & 69 \\
\hline Number of farm partners & count & 2.0 & 1.3 & -0.05 & 0.35 & & 61 \\
\hline CSA is run by a manager rather than a farm partner & binary & 0.08 & 0.27 & 0.10 & 0.22 & & 67 \\
\hline Has a 4-year degree (Farmer A) & binary & 0.77 & 0.43 & -0.12 & 0.16 & & 69 \\
\hline Has a graduate degree (Farmer A) & binary & 0.20 & 0.41 & -0.04 & 0.36 & & 69 \\
\hline Gender is female (Farmer A) & binary & 0.52 & 0.50 & -0.20 & 0.05 & * & 68 \\
\hline Race is white (Farmer A) & binary & 0.86 & 0.35 & 0.19 & 0.06 & $\circ$ & 64 \\
\hline Percentage of farm partners who are female & continuous & 0.43 & 0.35 & -0.10 & 0.20 & & 68 \\
\hline \multicolumn{8}{|l|}{ Farmer satisfaction variables, indicates level of satisfaction with: } \\
\hline Financial ability to meet annual operating costs & Likert $^{1}$ & 3.1 & 1.1 & 0.18 & 0.14 & & 67 \\
\hline Farmer compensation & Likert $^{1}$ & 2.7 & 1.1 & 0.31 & 0.01 & $* * *$ & 67 \\
\hline Financial security for farmer including health insurance, retirement, etc. & Likert $^{1}$ & 2.2 & 1.1 & 0.14 & 0.26 & & 66 \\
\hline Financial ability to build and maintain physical farm infrastructure & Likert $^{1}$ & 2.9 & 1.1 & 0.11 & 0.37 & & 66 \\
\hline Farmer stress level/quality of life & Likert $^{1}$ & 3.2 & 1.0 & 0.33 & 0.01 & $* * *$ & 66 \\
\hline Maintenance or improvement of soil quality & Likert $^{1}$ & 3.9 & 0.9 & 0.34 & 0.00 & $* * *$ & 67 \\
\hline Workload for the farmer & Likert $^{1}$ & 3.0 & 0.9 & 0.23 & 0.06 & $\circ$ & 67 \\
\hline Compensation for other workers & Likert $^{1}$ & 3.1 & 1.1 & 0.08 & 0.53 & & 59 \\
\hline Workload for other workers & Likert $^{1}$ & 3.6 & 0.9 & 0.21 & 0.11 & & 59 \\
\hline Community involvement & Likert $^{1}$ & 3.5 & 1.2 & 0.13 & 0.29 & & 67 \\
\hline Average of all satisfaction variables & Likert index & 3.1 & 0.7 & 0.34 & 0.01 & $* * *$ & 67 \\
\hline
\end{tabular}

^ Two different correlation coefficients are shown, depending on the appropriate correlation test: (1) Pearson's $r$ coefficient, between retention rate and continuous (including count, count index, index, percentage, and year) and binary variable types; and (2) Spearman's rho coefficient, between retention rate and ordinal (including Likert and Likert index) variable types. + significance here is highlighted as follows: $\leq 0.10$ and $>0.05={ }^{\circ}, 0.05=*$, and $\leq 0.01=$ $* * * .15=$ very satisfied to $1=$ very unsatisfied.

Correlations between retention rates and farmer satisfaction variables show that they are highly related. Satisfaction with farmer compensation $(p=0.01)$, farmer stress level/quality of life $(p=0.01)$, maintenance or improvement of soil quality $(p=0.00)$, and the average of all the satisfaction variables $(p=0.01)$ were all moderately correlated with retention. This is in line with the findings of Tegtmeier and Duffy [26]. Most likely, higher retention rates directly contribute to greater farmer satisfaction on a variety of fronts, since higher retention means less worry about economic stability, and less work to try to enroll new members. There could also be a virtuous cycle, as less stressed farmers might have more time to devote to relationship building and marketing, and/or a satisfied farmer's vibe is more likely to attract and retain members.

\subsection{Farm Variables: Correlations}

Table 4 shows that CSA retention was not correlated with the CSA's age, the farm's size, or land ownership, nor with whether the CSA focuses on horticultural crops or livestock or a mix of the two. In contrast, management in relation to organic standards (we asked about how similar farms' practices were to certified organic production, generally the norm in CSAs in California [2,5]) had one significant relationship. The variable most but not all of practices are in line with organic rules was moderately negatively correlated with retention $(p=0.01)$. This variable captured whether CSAs are using some synthetic inputs (fertilizers or pesticides) that would not be allowed by organic standards. The result suggests that CSA members really want farming that is in line with organic standards. The certification variables that are most highly correlated are biodynamic certified $(p=0.09)$ and has another certification ( $p=0.07$, which is a certification other than organic and biodynamic); these results suggest that going beyond organic certification might be an important indicator to consumers, or that farmers with dispositions to take on the often-onerous work of certification might also be good at customer service tasks. 
Table 4. Correlations of farm variables with member retention.

\begin{tabular}{|c|c|c|c|c|c|c|c|}
\hline & \multicolumn{3}{|c|}{ Variable Descriptors } & \multicolumn{4}{|c|}{ Correlation with Member Retention } \\
\hline & Variable Type & Mean & St. Dev. & Coefficient $(r)$ & $p$-Valu & & $n$ \\
\hline \multicolumn{8}{|l|}{ Farm characteristic variables } \\
\hline Year CSA started & year & 2006 & 7 & -0.09 & 0.24 & & 69 \\
\hline Farm size (total acres) & continuous & 257 & 989 & 0.12 & 0.16 & & 69 \\
\hline Percentage of land owned & percentage & 0.44 & 0.47 & 0.00 & 0.50 & & 48 \\
\hline Horticulturally-focused farm & binary & 0.49 & 0.50 & 0.06 & 0.32 & & 69 \\
\hline Horticulture-and-livestock-focused farm & binary & 0.48 & 0.50 & -0.05 & 0.33 & & 69 \\
\hline Livestock-focused farm & binary & 0.03 & 0.17 & -0.01 & 0.46 & & 69 \\
\hline \multicolumn{8}{|l|}{ Organic management variables } \\
\hline Organically certified & binary & 0.46 & 0.50 & 0.05 & 0.36 & & 68 \\
\hline Follows organic rules but the farm is not certified & binary & 0.37 & 0.49 & -0.08 & 0.25 & & 68 \\
\hline Considers practices to be beyond organic & binary & 0.46 & 0.50 & 0.12 & 0.16 & & 68 \\
\hline Biodynamic certified & binary & 0.09 & 0.29 & 0.16 & 0.09 & $\circ$ & 68 \\
\hline Most but not all of practices are in line with organic rules & binary & 0.10 & 0.31 & -0.35 & 0.00 & $* * *$ & 68 \\
\hline Farms with synthetic pesticides & binary & 0.03 & 0.17 & 0.14 & 0.13 & & 68 \\
\hline Farms with synthetic fertilizers & binary & 0.06 & 0.24 & 0.07 & 0.29 & & 68 \\
\hline Has another certification & binary & 0.09 & 0.29 & 0.18 & 0.07 & $\circ$ & 68 \\
\hline Has any certification & binary & 0.53 & 0.50 & 0.12 & 0.16 & & 68 \\
\hline Uses organic practices (whether certified or not) & binary & 0.96 & 0.21 & 0.14 & 0.13 & & 68 \\
\hline \multicolumn{8}{|l|}{ Crop type variables } \\
\hline Diversity of crop types (count of variables below) & count (index) & 2.6 & 1.3 & 0.21 & 0.03 & ** & 69 \\
\hline Grows vegetables & binary & 0.96 & 0.21 & 0.09 & 0.24 & & 67 \\
\hline Grows fruit & binary & 0.79 & 0.41 & 0.30 & 0.01 & $* * *$ & 67 \\
\hline Grows nuts & binary & 0.12 & 0.33 & 0.24 & 0.03 & $* *$ & 67 \\
\hline Grows grains & binary & 0.18 & 0.39 & -0.03 & 0.40 & & 67 \\
\hline Grows oil crops & binary & 0.01 & 0.12 & -0.08 & 0.27 & & 67 \\
\hline Grows (animal) feed crops & binary & 0.12 & 0.33 & -0.16 & 0.09 & $\circ$ & 67 \\
\hline Grows flowers & binary & 0.34 & 0.48 & 0.36 & 0.00 & $* * *$ & 67 \\
\hline Grows other crops & binary & 0.12 & 0.33 & -0.13 & 0.14 & & 67 \\
\hline \multicolumn{8}{|l|}{ Livestock type variables } \\
\hline Raises livestock & binary & 0.51 & 0.50 & -0.10 & 0.20 & & 69 \\
\hline Diversity of livestock types (as a count of variables below) & count (index) & 1.1 & 1.5 & -0.10 & 0.21 & & 70 \\
\hline Raises layers & binary & 0.39 & 0.49 & -0.01 & 0.48 & & 69 \\
\hline Raises broilers & binary & 0.03 & 0.17 & -0.07 & 0.29 & & 69 \\
\hline Raises other poultry & binary & 0.10 & 0.30 & -0.14 & 0.13 & & 69 \\
\hline Raises hogs & binary & 0.06 & 0.24 & -0.01 & 0.47 & & 69 \\
\hline Raises lambs & binary & 0.16 & 0.37 & -0.15 & 0.11 & & 69 \\
\hline Raises goats & binary & 0.12 & 0.32 & -0.07 & 0.27 & & 69 \\
\hline Raises dairy cows & binary & 0.04 & 0.21 & 0.07 & 0.29 & & 69 \\
\hline Raises beef cattle & binary & 0.12 & 0.32 & 0.09 & 0.22 & & 69 \\
\hline Raises llamas & binary & 0.04 & 0.21 & 0.03 & 0.40 & & 69 \\
\hline Raises other livestock (other than the ones listed above) & binary & 0.04 & 0.21 & -0.24 & 0.02 & ** & 69 \\
\hline
\end{tabular}

† significance here is highlighted as follows: $\leq 0.10$ and $>0.05={ }^{\circ}, \leq 0.05$ and $>0.01=* *$, and $\leq 0.01=* * *$.

Retention was positively correlated with diversity of crop types $(p=0.03)$. Retention rates are higher if the farm grows fruit $(p=0.01)$, grows nuts $(p=0.03)$, or grows flowers $(p=0.01)$. Grows flowers was the farm management variable with the strongest positive correlation with retention. Specific types of livestock were not correlated with retention but raises other livestock (different from the ones we specifically asked about) was negatively associated with retention $(p=0.02)$. Why this is the case is not clear, but it could be a lack of general demand for very non-traditional animal products or suggests a less economically-focused management approach.

\subsection{Economic Variables: Correlations}

Four economic variables were significant at the $5 \%$ level (Table 5). A moderate correlation exists between retention rate and the competition index that Galt et al. [9] created. This competition index is a combination of "farmers' perceptions of the strength of competition they face" together with whether farmers would like to raise their share prices but "feel constrained by competition in their ability to raise their CSA share prices" [9] (p. 497). The first half of the variable was calculated by averaging each farmer's perceived level of competition with four market outlets: other CSAs; other direct market channels such as farmers' markets; retail market channels such as grocery stores; and grocery home delivery services (this was quantified on a 0 to 1 scale, from "non-existent" to "very strong" for each market channel, then averaged). The second half of the index was a binary variable determined by whether the farmer wanted to raise share prices but felt constrained by competition in doing 
so [9] (pp. 497-498). Since half of the index is defined by farmers' perceptions of competition, it was likely influenced by their retention rates, since increased competition can manifest in more difficulty retaining members.

Table 5. Correlations of economic variables with member retention.

\begin{tabular}{|c|c|c|c|c|c|c|c|}
\hline & \multicolumn{3}{|c|}{ Variable Descriptors } & \multicolumn{4}{|c|}{$\begin{array}{c}\text { Correlation with Member } \\
\text { Retention }\end{array}$} \\
\hline & Variable Type & Mean & St. Dev. & $\begin{array}{l}\text { Coefficient } \\
(r \text { or } r h o)^{\wedge}\end{array}$ & $p$-Va & & $n$ \\
\hline \multicolumn{8}{|l|}{ Competition variables } \\
\hline Competition index & index & 1.0 & 0.6 & -0.34 & 0.00 & $* * *$ & 61 \\
\hline \multicolumn{8}{|l|}{ Market channel variables } \\
\hline Percentage of income through CSA & percentage & 0.42 & 0.31 & 0.11 & 0.17 & & 69 \\
\hline Percentage of income farmers' market(s) & percentage & 0.23 & 0.26 & -0.02 & 0.43 & & 69 \\
\hline Percentage of income through on-farm stand & percentage & 0.06 & 0.15 & -0.03 & 0.41 & & 69 \\
\hline Percentage of income through mail & percentage & 0.02 & 0.05 & 0.07 & 0.29 & & 69 \\
\hline Percentage of income through other direct market channel & percentage & 0.05 & 0.14 & 0.04 & 0.37 & & 69 \\
\hline Percentage of income directly to retail outlets & percentage & 0.14 & 0.19 & -0.03 & 0.40 & & 69 \\
\hline Percentage of income wholesale & percentage & 0.06 & 0.17 & -0.15 & 0.10 & $\circ$ & 69 \\
\hline Percentage of income generated through services & percentage & 0.02 & 0.06 & -0.02 & 0.45 & & 69 \\
\hline \multicolumn{8}{|l|}{ Financial variables } \\
\hline Off-farm job (held by at least one farm partner) & binary & 0.48 & 0.50 & -0.25 & 0.03 & ** & 61 \\
\hline Off-farm income covers household expenses & ordinal $^{1}$ & 1.3 & 1.2 & 0.04 & 0.38 & & 65 \\
\hline Off-farm income covers farm expenses & ordinal $^{1}$ & 0.7 & 1.0 & -0.01 & 0.48 & & 60 \\
\hline Annual salary for Farmer A & continuous & $\$ 16,996$ & $\$ 35,479$ & -0.18 & 0.16 & & 34 \\
\hline Annual salary total for all farm partners & continuous & $\$ 23,242$ & $\$ 37,257$ & -0.21 & 0.12 & & 33 \\
\hline Management worker hourly wage & continuous & $\$ 13.05$ & $\$ 10.84$ & 0.13 & 0.29 & & 19 \\
\hline Year-round farmworker hourly wage & continuous & $\$ 10.78$ & $\$ 2.72$ & 0.41 & 0.01 & $* * *$ & 32 \\
\hline Seasonal farmworker hourly wage & continuous & $\$ 8.83$ & $\$ 3.86$ & 0.22 & 0.12 & & 29 \\
\hline Percent of market outlets that are profitable & percentage & 0.58 & 0.41 & 0.16 & 0.10 & $\circ$ & 68 \\
\hline The CSA is profitable & binary & 0.59 & 0.50 & 0.08 & 0.27 & & 68 \\
\hline The CSA is as profitable as the farmer(s) want(s) & binary & 0.28 & 0.45 & 0.36 & 0.00 & $* * *$ & 68 \\
\hline
\end{tabular}

^ Two different correlation coefficients are shown, depending on the appropriate correlation test: (1) Pearson's $r$ coefficient, between retention rate and continuous (including count, count index, index, percentage, and year) and binary variable types; and (2) Spearman's rho coefficient, between retention rate and ordinal (including Likert and Likert index) variable types. + significance here is highlighted as follows: $\leq 0.10$ and $>0.05={ }^{\circ}, \leq 0.05$ and $>0.01={ }^{* *}$, and $\leq 0.01={ }^{* * *} \cdot{ }^{1} 0=$ none, $1=$ moderately, $2=$ heavily, $3=$ completely.

There were no correlations between farmers using different market channels and CSA retention rates, except for percentage of income through wholesale, which was significant at the $10 \%$ level. In terms of correlations, pursuing other market channels does not negatively affect a farm's CSA member retention, which is helpful to know since other research has shown that a CSA's profitability is negatively associated with the percentage of total sales through its CSA [7]. Pursuing other market channels thus continues to be a good economic strategy for California CSAs.

There are a few financial variables moderately correlated with retention rate. Holding an off-farm job (held by at least one farm partner) was negatively associated with retention $(p=0.03)$. This could be causal in both directions: It could divert labor and attention away from the CSA and thereby undermine retention efforts, but externally-earned income might also help a CSA struggling with retention, making it more likely for CSAs with low retention rates to have partners with off-farm work. CSA farms tend to have off-farm work rates for farm partners (42\%) that are considerably lower than all organic farms in California (67.7\%), and farms generally in the USA (66\%) [2] (p. 23). The negative correlation suggests that there might be disadvantages to off-farm work for CSA farmers, but more research is needed to explain the relationship.

The other two financial variables significantly correlated with retention rate were year-round farmworker hourly wage ( $p=0.01)$ and the CSA is as profitable as the farmer $(s)$ want $(s)(p=0.01)$. Both of these are likely consequences of high retention rates. Higher levels of retention allow for more economic stability and profitability for CSAs. For California CSAs, this translates into higher wages for permanent farmworkers (see also [27]). 


\subsection{Region Variables: Correlations}

We examined the relationship between retention rates and CSA farm locations within a region, and the region that farmers identified as their primary market region (for both analyses, we collected data at the county level, and then aggregated county-level data to create the regional data described in Tables 1 and 6). Farm location was only significantly correlated with retention for one region: the farm region of the Central Coast has a positive relationship $(p=0.04)$. Having a primary market region of the Central Coast was also positively correlated with retention $(p=0.05)$. On the other hand, having a primary market of the Delta/East Bay was moderately negatively correlated with retention $(p=0.01)$. Regional differences matter: It might be that members are more loyal and/or that markets are less saturated in the Central Coast, while members might be less loyal and/or markets heavily saturated in the Delta/East Bay. As Galt et al. [9] note in regard to CSAs and competition, determining market saturation geographically is very difficult, as it would require determining the proportion of a general population of a region that would be loyal CSA consumers, rather than just a CSA per capita calculation. Nevertheless, these data suggest that market saturation caused by competition within the Delta/East Bay is likely driving down retention rates for CSAs with primary CSA markets in this region.

Table 6. Correlations of region variables with member retention.

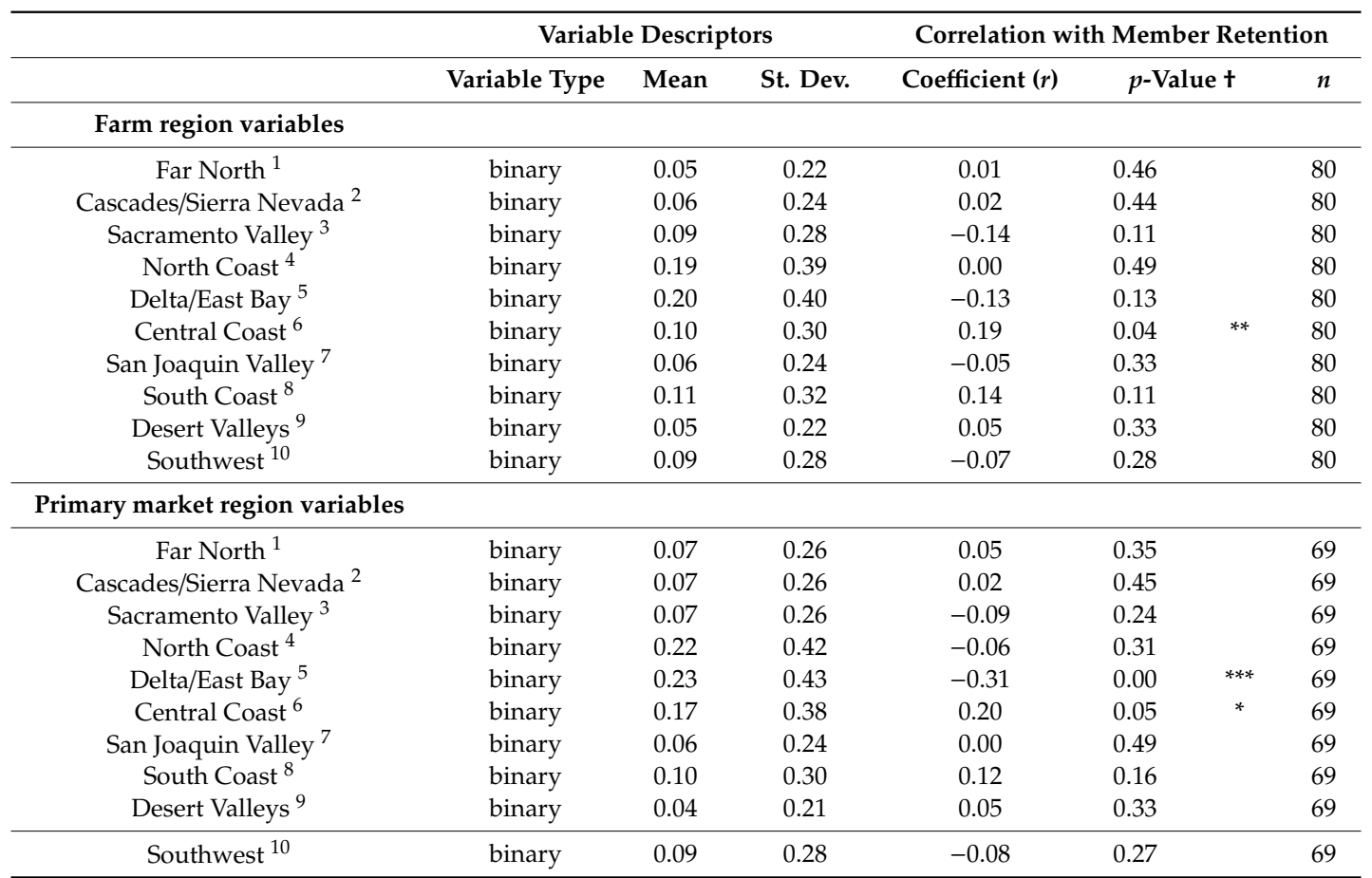

† significance here is highlighted as follows: $0.05=^{*}, \leq 0.05$ and $>0.01=^{* *}$, and $\leq 0.01={ }^{* * *}$. ${ }^{1}$ Del Norte, Humboldt, Shasta, Siskiyou, and Trinity Counties. ${ }^{2}$ Alpine, Amador, Calaveras, El Dorado, Inyo, Lassen, Modoc, Mono, Nevada, Placer, Plumas, Sierra, and Tuolumne Counties. ${ }^{3}$ Butte, Colusa, Glenn, Sutter, Tehama, and Yuba Counties.

${ }^{4}$ Lake, Marin, Mendocino, Napa, and Sonoma Counties. ${ }^{5}$ Alameda, Contra Costa, Sacramento, Solano, and Yolo Counties. ${ }^{6}$ Monterey, San Benito, San Francisco, San Mateo, Santa Clara, and Santa Cruz Counties. ${ }^{7}$ Fresno, Kern, Kings, Madera, Mariposa, Merced, San Joaquin, Stanislaus, and Tulare Counties. ${ }^{8}$ San Luis Obispo, Santa Barbara, and Ventura Counties. ${ }^{9}$ Imperial, Riverside, and San Bernardino Counties. ${ }^{10}$ Los Angeles, Orange, and San Diego Counties.

\subsection{A Model to Theorize Directionality}

Figure 1 operationalizes the 23 variables significantly correlated with retention at the $5 \%$ level, as summarized in Table 7, in a simple causal model organized into five colors representing the general category of the variable: Farm (green), region (blue), economic (red), farmer (purple), and CSA (yellow). Based largely on political economic theory as applied to alternative food networks [7,9,27], the model theorizes what is causing retention rates to vary, and the resulting consequences. The factors likely 
affecting retention rates have arrows pointing into the retention rate box, while those factors we theorize as the consequences of retention rates have arrows emanating into the theorized outcomes. Rather than a representation of the overall findings, it is a crucial step in pursuing our next analysis, which is a series of multiple regression models that hold constant other variables to see whether the bivariate correlations continue to be significant in relation to other (perhaps co-varying) variables.

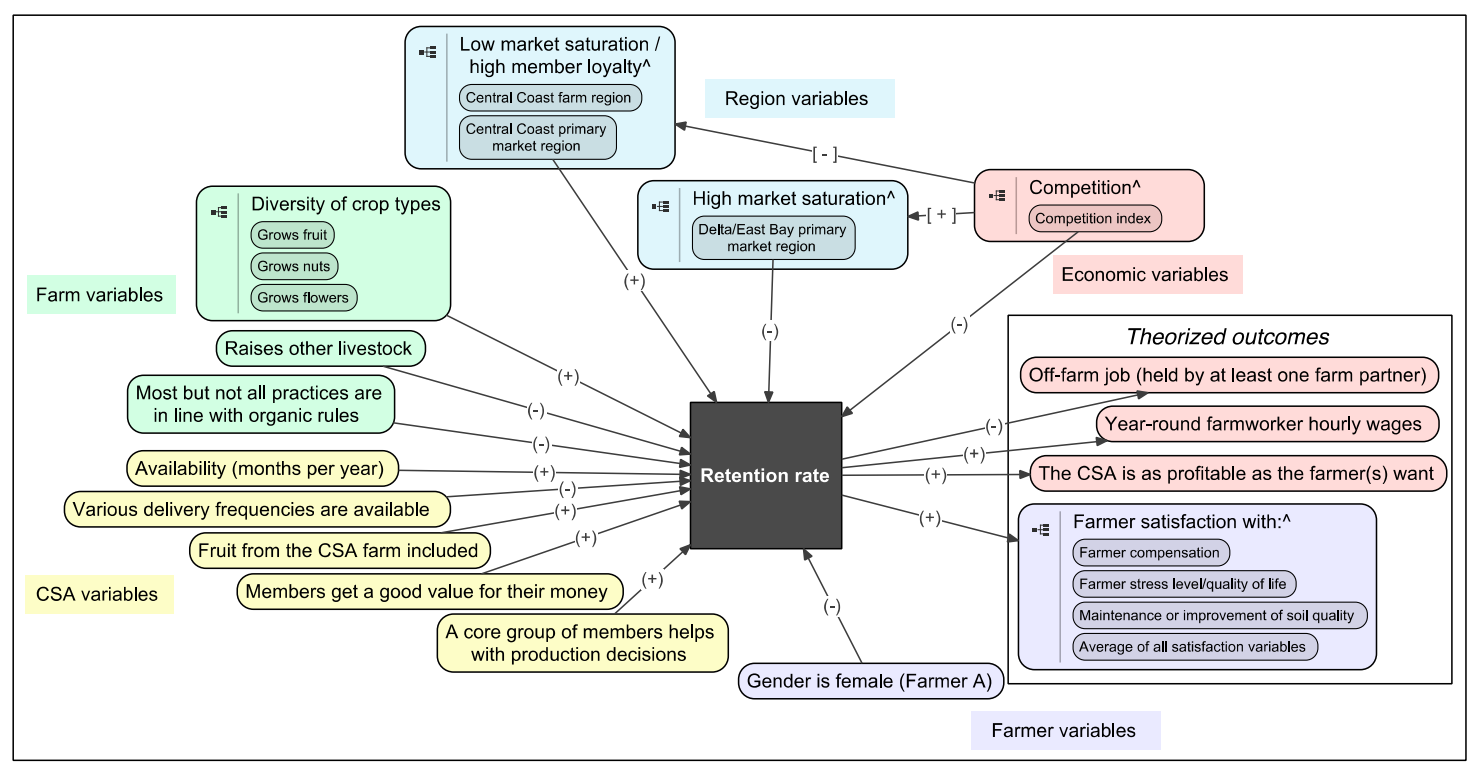

Figure 1. A simple causal model theorizing relationships between retention rate and significantly correlated variables (only variables from Table 7 significant at the $5 \%$ level are shown). ^ categories of variables, rather than variables themselves.

The diagram in Figure 1 theorizes that there are political economic forces about which CSAs can do little, but that nonetheless impact CSA. Higher levels of competition lead to lower retention rates, which cause negative outcomes: the CSA is more likely to not be as profitable as farm partners would like, which leads to lower farmer satisfaction, and lower wages for year-round workers. The reverse is true as well: Lower levels of competition allow for higher retention rates, creating positive outcomes; thus, the CSA is more likely to be as profitable as the farm partners would like, leading to higher farmer satisfaction and higher wages for year-round workers. Our theorization of the data also suggests that larger cultural forces of sexism, and racism to a lesser extent, could be impacting CSA farmers, with female CSA farmers and CSA farmers of color having lower retention rates (although we do not know if this is the case until other factors are controlled for, as done below in the multiple regression analysis). 
Table 7. Summary of significant correlations with member retention (at the $10 \%$ level).

\begin{tabular}{|c|c|c|c|c|c|c|c|c|}
\hline & & \multicolumn{3}{|c|}{ Variable Descriptors } & \multicolumn{4}{|c|}{ Correlation with Member Retention } \\
\hline & & $\begin{array}{l}\text { Variable } \\
\text { Type }\end{array}$ & Mean & St. Dev. & $\begin{array}{l}\text { Coefficient } \\
(r \text { or } r h o)^{\wedge}\end{array}$ & $p$-Va & & $n$ \\
\hline \multirow{11}{*}{$\begin{array}{c}\text { CSA } \\
\text { management } \\
\text { variables }\end{array}$} & Share configuration variables & & & & & & & \\
\hline & Availability (months per year) & continuous & 8.8 & 2.7 & 0.20 & 0.05 & * & 68 \\
\hline & $\begin{array}{l}\text { Various delivery frequencies available (e.g., each } \\
\text { week, etc.) }\end{array}$ & binary & 0.38 & 0.49 & -0.25 & 0.01 & $* * *$ & 76 \\
\hline & Share content variables & & & & & & & \\
\hline & Fruit from the CSA farm included & ordinal $^{1}$ & 2.0 & 1.5 & 0.29 & 0.01 & $* * *$ & 76 \\
\hline & Flowers from the CSA farm always included & binary & 0.1 & 0.4 & 0.20 & 0.09 & $\circ$ & 76 \\
\hline & Member-farm relationship variables & & & & & & & \\
\hline & Members get a good value for their money & Likert $^{2}$ & 4.5 & 0.7 & 0.28 & 0.01 & *** & 77 \\
\hline & $\begin{array}{c}\text { A core group of members helps with production } \\
\text { decisions }\end{array}$ & binay & 0.03 & 0.16 & 0.22 & 0.03 & $* *$ & 73 \\
\hline & Member number and population variables & & & & & & & \\
\hline & Population per CSA in primary market(s) & continuous & 160,528 & 202,247 & -0.17 & 0.08 & $\circ$ & 69 \\
\hline \multirow{9}{*}{$\begin{array}{c}\text { Farmer } \\
\text { variables }\end{array}$} & Farmer demographic variables & & & & & & & \\
\hline & Gender is female (Farmer A) & binary & 0.52 & 0.50 & -0.20 & 0.05 & * & 68 \\
\hline & Race is white (Farmer A) & binary & 0.86 & 0.35 & 0.19 & 0.06 & $\circ$ & 64 \\
\hline & Farmer satisfaction variables & & & & & & & \\
\hline & Farmer compensation & Likert $^{3}$ & 2.7 & 1.1 & 0.29 & 0.01 & $* * *$ & 67 \\
\hline & Farmer stress level/quality of life & Likert $^{3}$ & 3.2 & 1.0 & 0.29 & 0.01 & $* * *$ & 66 \\
\hline & Maintenance or improvement of soil quality & Likert $^{3}$ & 3.9 & 0.9 & 0.35 & 0.00 & $* * *$ & 67 \\
\hline & Workload for the farmer & Likert $^{3}$ & 3.0 & 0.9 & 0.23 & 0.06 & $\circ$ & 67 \\
\hline & Average of all satisfaction variables & Likert index & 3.1 & 0.7 & 0.34 & 0.01 & $* * *$ & 67 \\
\hline \multirow{12}{*}{ Farm variables } & Organic management variables & & & & & & & \\
\hline & Biodynamic certified & binary & 0.09 & 0.29 & 0.16 & 0.09 & $\circ$ & 68 \\
\hline & $\begin{array}{l}\text { Most but not all practices are in line with organic } \\
\text { rules }\end{array}$ & binary & 0.10 & 0.31 & -0.35 & 0.00 & $* * *$ & 68 \\
\hline & Has another certification & binary & 0.09 & 0.29 & 0.18 & 0.07 & $\circ$ & 68 \\
\hline & Crop type variables & & & & & & & \\
\hline & Diversity of crop types & count & 2.6 & 1.3 & 0.21 & 0.03 & $* *$ & 69 \\
\hline & Grows fruit & binary & 0.79 & 0.41 & 0.30 & 0.01 & $* * *$ & 67 \\
\hline & Grows nuts & binary & 0.12 & 0.33 & 0.24 & 0.03 & $* *$ & 67 \\
\hline & Grows (animal) feed crops & binary & 0.12 & 0.33 & -0.16 & 0.09 & $\circ$ & 67 \\
\hline & Grows flowers & binary & 0.34 & 0.48 & 0.36 & 0.00 & $* * *$ & 67 \\
\hline & Livestock type variables & & & & & & & \\
\hline & Raises other livestock & binary & 0.04 & 0.21 & -0.24 & 0.02 & $* *$ & 69 \\
\hline \multirow{9}{*}{$\begin{array}{l}\text { Economic } \\
\text { variables }\end{array}$} & Competition variables & & & & & & & \\
\hline & Competition index & index & 1.0 & 0.6 & -0.34 & 0.00 & $* * *$ & 61 \\
\hline & Market channel variables & & & & & & & \\
\hline & Percentage of income wholesale & percentage & 0.06 & 0.17 & -0.15 & 0.10 & $\circ$ & 69 \\
\hline & Finance variables & & & & & & & \\
\hline & Off-farm job (held by at least one farm partner) & binary & 0.48 & 0.50 & -0.25 & 0.03 & $* *$ & 61 \\
\hline & Year-round farmworker hourly wage & continuous & $\$ 10.78$ & $\$ 2.72$ & 0.41 & 0.01 & $* * *$ & 32 \\
\hline & Percent of market outlets that are profitable & percentage & 0.58 & 0.41 & 0.16 & 0.10 & $\circ$ & 68 \\
\hline & The CSA is as profitable as the farmer(s) want(s) & binary & 0.28 & 0.45 & 0.36 & 0.00 & $* * *$ & 68 \\
\hline \multirow{5}{*}{$\begin{array}{c}\text { Region } \\
\text { variables }\end{array}$} & Farm region variables & & & & & & & \\
\hline & Central Coast ${ }^{4}$ & binary & 0.10 & 0.30 & 0.19 & 0.04 & $* *$ & 80 \\
\hline & Primary market region variables & & & & & & & \\
\hline & Delta/East Bay ${ }^{5}$ & binary & 0.23 & 0.43 & -0.31 & 0.00 & *** & 69 \\
\hline & Central Coast $^{4}$ & binary & 0.17 & 0.38 & 0.20 & 0.05 & * & 69 \\
\hline
\end{tabular}

† significance here is highlighted as follows: $\leq 0.10$ and $>0.05={ }^{\circ}, 0.05=*, \leq 0.05$ and $>0.01={ }^{* *}$, and $\leq 0.01={ }^{* * *}$. 14 = always, $3=$ most of the time, $2=$ sometimes, $1=$ infrequently, $0=$ never. ${ }^{2} 5=$ strongly agree, etc., $1=$ strongly disagree. ${ }^{3} 5=$ very satisfied, etc., 1 = very unsatisfied. ${ }^{4}$ Monterey, San Benito, San Francisco, San Mateo, Santa Clara, and Santa Cruz Counties. ${ }^{5}$ Alameda, Contra Costa, Sacramento, Solano, and Yolo Counties. 


\subsection{Ordinary Least Squares Regression Models to Control for Other Variables}

We created five ordinary least squares (OLS) multiple regression models with retention rate as the dependent variable in order to examine the influence of independent variables while controlling for other independent variables. We started with the list of independent variables that were correlated in Tables 1-6, while excluding variables that we theorized in Figure 1 to be consequences of retention rates. We then tested a very wide range of other independent variables, many of which had to be excluded for reasons of multicollinearity. Model 1 in Table 8 shows the model we arrived at with the greatest fit after many iterations. We also conducted various tests to examine multicollinearity, heteroscedasticity (linear and non-linear), and model specification; the results are shown in the bottom of Table 8 , and reveal that multicollinearity and heteroscedasticity are not significant problems, and that the model is well-specified. Model 1 uses all 10 dummy variables for primary market region as control variables, thereby controlling for the wide variation in retention rates across region.

Using Model 1 as the base, we then re-tested the other significant variables (at the 5\% and 10\% levels) from Tables 1-6 to examine their effects and test the robustness of the associations in Model 1. We discuss these other models briefly here. Model 2 included additional CSA management variables and showed that the variable members form a supportive community around the farm is significantly positively associated with retention. As this is a statement of farmer perception and is likely highly influenced by the farm's retention rate, we did not include it in any models other than Model 2 . Model 3 included binary race and gender variables_race is white (Farmer $A$ ) and gender is female (Farmer A) -and shows that, when other relationships are considered, race and gender are not significantly correlated with retention. This suggests that race and gender are instead correlated with some management characteristics and/or regions, and that when these management and regional variables are held constant, gender and race do not influence retention directly. Model 4 included farm-level variables and shows that raises other livestock is negatively associated with retention rates. A CSA focused on animal-derived fiber in the dataset has a very low retention rate, which helps make sense of this variable, but its low relevance to the CSA population means we chose to exclude it from Model 1. Lastly, for Model 5, the economic/financial variable of percent of market outlets that are profitable was included, but was not significant, suggesting that a successful focus on other markets does not detract from CSA retention (see also [7]). For all models, we examined multicollinearity, heteroscedasticity (linear and non-linear), and model specification; as with Model 1, multicollinearity and heteroscedasticity were not problems, and model specification was good. Additionally, all models were tested for the problem of omitted variables (results are not shown), and all passed the test.

Considering the five OLS models together, we tallied the number of times that the variables in Model 1 were significant across all five models. We call this "consistency," and when it is more than $60 \%$ across the five models it is shown in grey fill in Table 8. Importantly, the variables that showed significance in Model 1 maintain their significance across the models, suggesting that their relationship with retention is quite robust, even when controlling for a range of other variables. For this reason, we rely upon Model 1 to make recommendations to CSA farmers and advocates below. 
Table 8. Ordinary least squares (OLS) regression models with retention rate as the dependent variable.

\begin{tabular}{|c|c|c|c|c|c|c|c|c|c|c|c|c|c|c|c|c|c|c|c|c|}
\hline & \multicolumn{4}{|c|}{ Model 1: } & \multicolumn{4}{|c|}{ Model 2: } & \multicolumn{4}{|c|}{ Model 3: } & \multicolumn{4}{|c|}{ Model 4: } & \multicolumn{4}{|c|}{ Model 5: } \\
\hline & \multicolumn{4}{|c|}{ Best Fit } & \multicolumn{4}{|c|}{ Best Fit + Management } & \multicolumn{4}{|c|}{ Best Fit + Farmer } & \multicolumn{4}{|c|}{ Best Fit + Farm } & \multicolumn{4}{|c|}{ Best Fit + Economics/Finances } \\
\hline & \multicolumn{4}{|c|}{ Num. obs. $=53$} & \multicolumn{4}{|c|}{ Num. obs. $=48$} & \multicolumn{4}{|c|}{ Num. obs. $=50$} & \multicolumn{4}{|c|}{ Num. obs. $=53$} & \multicolumn{4}{|c|}{ Num. obs. $=52$} \\
\hline & \multicolumn{4}{|c|}{$F(8,43)=4.35$} & \multicolumn{4}{|c|}{$F(7,34)=4.42$} & \multicolumn{4}{|c|}{$F(12,34)=4.08$} & \multicolumn{4}{|c|}{$F(10,38)=3.75$} & \multicolumn{4}{|c|}{$F(12,39)=3.91$} \\
\hline & \multicolumn{4}{|c|}{$p$-Value $=0.00$} & & $p$-Value & $=0.00$ & & & $p$-Value & 0.00 & & & $p$-Value $=$ & $=0.00$ & & & $p$-Value $=$ & $=0.00$ & \\
\hline & & & $=0.66$ & & & $R^{2}=$ & & & & $R^{2}=$ & & & & $R^{2}=0$ & & & & $R^{2}=0$ & & \\
\hline Dependent variable: & & Adj. & $2=0.51$ & & & Adj. $R^{2}$ & $=0.58$ & & & Adj. $R^{2}$ & 0.53 & & & Adj. $R^{2}=$ & $=0.51$ & & & Adj. $R^{2}=$ & $=0.49$ & \\
\hline Retention rate & & $\operatorname{Root} \mathrm{M}$ & $\mathrm{E}=14.79$ & & & oot MSE & $=12.71$ & & & oot MSE & $=14.77$ & & & oot MSE & $=14.69$ & & & oot MSE & $=15.15$ & \\
\hline Independent variables ^ & Coeff. & $t$ & $p$-Value $\mathrm{t}$ & Coeff. & $t$ & $p$-Va & uet $t$ & Coeff. & $t$ & $p$-Va & & Coeff. & $t$ & $p$-Val & uet & Coeff. & $t$ & $p$-Val & & \\
\hline Availability (months per year) & 2.76 & 2.34 & 0.03 & ${ }^{* *}$ & 2.43 & 2.24 & 0.03 & ${ }^{* *}$ & 2.98 & 2.46 & 0.02 & ${ }^{* *}$ & 1.43 & 1.07 & 0.29 & & 2.57 & 2.04 & 0.05 & * \\
\hline Fruit from the CSA farm included & 8.57 & 4.70 & 0.00 & ${ }^{* * *}$ & 8.64 & 4.89 & 0.00 & $* * *$ & 8.94 & 4.52 & 0.00 & ${ }^{* * *}$ & 8.55 & 3.97 & 0.00 & **** & 8.95 & 4.40 & 0.00 & $* * *$ \\
\hline Most but not all practices are in line with organic rules & -31.05 & -3.70 & 0.00 & $* * *$ & -18.27 & -2.28 & 0.03 & ** & -28.09 & -3.19 & 0.00 & $* * *$ & -25.72 & -2.92 & 0.01 & ** & -31.34 & -3.62 & 0.00 & $* * *$ \\
\hline Diversity of crop types & 5.36 & 2.52 & 0.02 & ** & 4.65 & 2.14 & 0.04 & ** & 4.04 & 1.79 & 0.08 & o & 4.69 & 1.57 & 0.13 & & 5.35 & 2.45 & 0.02 & $*^{* *}$ \\
\hline Competition index & -11.48 & -2.75 & 0.01 & ** & -12.62 & -3.08 & 0.01 & **** & -10.84 & -2.54 & 0.02 & ** & -9.92 & -2.32 & 0.03 & ** & -11.43 & -2.47 & 0.02 & *** \\
\hline Percentage of income wholesale & -0.43 & -1.72 & 0.10 & o & -0.43 & -1.94 & 0.06 & o & -0.42 & -1.61 & 0.12 & & -0.49 & -1.84 & 0.08 & 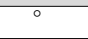 & -0.48 & -1.77 & 0.09 & 5 \\
\hline Far North is primary market & -12.30 & -1.16 & 0.25 & & -24.96 & -1.85 & 0.08 & $\circ$ & -15.21 & -1.43 & 0.16 & & -17.57 & -1.57 & 0.13 & & -13.10 & -1.20 & 0.24 & \\
\hline Cascades/Sierra Nevada is primary market & 6.93 & 0.63 & 0.53 & & -2.05 & -0.16 & 0.87 & & 4.15 & 0.37 & 0.72 & & 1.21 & 0.10 & 0.92 & & 6.83 & 0.60 & 0.55 & \\
\hline Sacramento Valley is primary market & 2.18 & 0.23 & 0.82 & & -13.33 & -1.22 & 0.23 & & -2.17 & -0.21 & 0.83 & & -6.32 & -0.56 & 0.58 & & 2.21 & 0.21 & 0.83 & \\
\hline North Coast is primary market & -17.24 & -2.11 & 0.04 & ${ }^{* *}$ & -28.38 & -3.00 & 0.01 & $* * *$ & -22.34 & -2.63 & 0.01 & ** & -22.08 & -2.30 & 0.03 & ** & -17.98 & -2.12 & 0.04 & ${ }^{* *}$ \\
\hline Delta/East Bay is primary market & -17.66 & -2.41 & 0.02 & ** & -24.05 & -3.23 & 0.00 & $* * *$ & -24.64 & -2.97 & 0.01 & ${ }^{* *}$ & -18.59 & -2.09 & 0.05 & * & -17.77 & -2.36 & 0.02 & $*^{* *}$ \\
\hline Central Coast is primary market & -15.47 & -1.69 & 0.10 & $\circ$ & -21.38 & -2.51 & 0.02 & ${ }^{* *}$ & -16.27 & -1.71 & 0.10 & $\circ$ & -14.28 & -1.41 & 0.17 & & -15.81 & -1.69 & 0.10 & \\
\hline San Joaquin Valley is primary market & -20.29 & -1.50 & 0.14 & & -29.94 & -2.36 & 0.03 & ** & -23.25 & -1.70 & 0.10 & $\circ$ & -14.46 & -0.78 & 0.44 & & -20.64 & -1.47 & 0.15 & \\
\hline South Coast is primary market & -23.54 & -2.02 & 0.05 & * & -31.74 & -2.64 & 0.01 & $* * *$ & -28.95 & -2.25 & 0.03 & ** & -22.98 & -1.88 & 0.07 & o & -20.59 & -1.59 & 0.12 & \\
\hline Desert Valleys is primary market & -0.37 & -0.03 & 0.97 & & -5.24 & -0.51 & 0.61 & & -5.20 & -0.46 & 0.65 & & -0.85 & -0.07 & 0.94 & & -0.16 & -0.01 & 0.99 & \\
\hline Southwest is primary market & -20.22 & -1.95 & 0.06 & $\circ$ & -18.54 & -1.47 & 0.15 & & -24.30 & -2.19 & 0.04 & $* *$ & -20.56 & -1.80 & 0.08 & $\circ$ & -20.10 & -1.89 & 0.07 & ${ }^{\circ}$ \\
\hline Members get a good value for their money & & & & & 4.51 & 1.15 & 0.26 & & & & & & & & & & & & & \\
\hline A core group of members helps with production decisions & & & & & -10.82 & -0.66 & 0.52 & & & & & & & & & & & & & \\
\hline Population per CSA in primary market(s) & & & & & 0.00 & -0.91 & 0.37 & & & & & & & & & & & & & \\
\hline Race is white (Farmer A) & & & & & & & & & 4.24 & 0.58 & 0.56 & & & & & & & & & \\
\hline Gender is female (Farmer A) & & & & & & & & & -1.60 & -0.34 & 0.74 & & & & & & & & & \\
\hline Biodynamic certified & & & & & & & & & & & & & 2.02 & 0.23 & 0.82 & & & & & \\
\hline Grows nuts & & & & & & & & & & & & & 9.85 & 0.85 & 0.40 & & & & & \\
\hline Grows (animal) feed crops & & & & & & & & & & & & & -1.78 & -0.16 & 0.87 & & & & & \\
\hline Raises other livestock & & & & & & & & & & & & & -23.26 & -1.91 & 0.07 & $\circ$ & & & & \\
\hline Percent of market outlets that are profitable & & & & & & & & & & & & & & & & & -0.91 & -0.14 & 0.89 & \\
\hline Constant & 38.15 & 2.73 & 0.01 & ** & 33.42 & 1.33 & 0.19 & & 39.13 & 2.62 & 0.01 & ** & 52.63 & 3.18 & 0.00 & $* * *$ & 39.94 & 2.70 & 0.01 & ${ }^{* *}$ \\
\hline
\end{tabular}


Table 8. Cont.

\begin{tabular}{|c|c|c|c|c|c|c|c|c|c|c|c|c|c|c|c|}
\hline & \multirow{2}{*}{\multicolumn{3}{|c|}{$\begin{array}{c}\text { Model 1: } \\
\text { Best Fit }\end{array}$}} & \multicolumn{3}{|c|}{ Model 2: } & \multicolumn{3}{|c|}{ Model 3: } & \multicolumn{3}{|c|}{ Model 4: } & \multicolumn{3}{|c|}{ Model 5: } \\
\hline & & & & \multicolumn{12}{|c|}{ Best Fit + Economics/Finances } \\
\hline Multicollinearity (variance inflation factor [VIF] test) & $\begin{array}{c}\text { VIF } \\
\text { Mean }\end{array}$ & $\begin{array}{c}\text { VIF } \\
\text { Min. }\end{array}$ & VIF Max. & $\begin{array}{c}\text { VIF } \\
\text { Mean }\end{array}$ & $\begin{array}{l}\text { VIF } \\
\text { Min. }\end{array}$ & $\begin{array}{l}\text { VIF } \\
\text { Max. }\end{array}$ & $\begin{array}{c}\text { VIF } \\
\text { Mean }\end{array}$ & $\begin{array}{l}\text { VIF } \\
\text { Min. }\end{array}$ & $\begin{array}{l}\text { VIF } \\
\text { Max. }\end{array}$ & $\begin{array}{c}\text { VIF } \\
\text { Mean }\end{array}$ & $\begin{array}{l}\text { VIF } \\
\text { Min. }\end{array}$ & $\begin{array}{l}\text { VIF } \\
\text { Max. }\end{array}$ & $\begin{array}{c}\text { VIF } \\
\text { Mean }\end{array}$ & $\begin{array}{l}\text { VIF } \\
\text { Min. }\end{array}$ & $\begin{array}{c}\text { VIF } \\
\text { Max. }\end{array}$ \\
\hline - & 1.95 & 1.33 & 3.00 & 2.67 & 1.38 & 5.33 & 1.96 & 1.28 & 3.02 & 2.49 & 1.47 & 4.20 & 1.98 & 1.45 & 3.05 \\
\hline Breusch-Pagan/Cook-Weisberg test for heteroscedasticity & $c h i^{2}$ & $p$-value & & $c h i^{2}$ & $p$-value & & $c h i^{2}$ & $p$-value & & $c h i^{2}$ & $p$-value & & $c h i^{2}$ & $p$-value & \\
\hline _ & 2.79 & 0.10 & & 0.93 & 0.34 & & 0.3 & 0.58 & & 0.02 & 0.88 & & 2.61 & 0.11 & \\
\hline White's test for non-linear forms of heteroscedasticity & $c h i^{2}$ & $p$-value & & $c h i^{2}$ & $p$-value & & $c h i^{2}$ & $p$-value & & $c h i^{2}$ & $p$-value & & $c h i^{2}$ & $p$-value & \\
\hline & 53 & 0.4354 & & 48 & 0.4321 & & 50 & 0.4334 & & 53 & 0.44 & & 52 & 0.4347 & \\
\hline Model specification & $t$ & $p$-value & & $t$ & $p$-value & & $t$ & $p$-value & & $t$ & $p$-value & & $t$ & $p$-value & \\
\hline _hat (variable of prediction) & 2.26 & 0.03 & & 3.04 & 0.00 & & 3.17 & 0.00 & & 3.17 & 0.00 & & 2.21 & 0.03 & \\
\hline _hatsq (variable of squared prediction) & -0.31 & 0.76 & & -1.14 & 0.26 & & -1.15 & 0.26 & & -0.79 & 0.43 & & -0.24 & 0.81 & \\
\hline
\end{tabular}

${ }^{\wedge}$ Grey fill shows variables for which a count of significance (at the $5 \%$ level) across all models is $\geq 60 \%$ (i.e., it is significant in at least three of five models). + significance here is highlighted as follows: $\leq 0.10$ and $>0.05={ }^{\circ}, 0.05=^{*}, \leq 0.05$ and $>0.01=* *$, and $\leq 0.01={ }^{* * *}$. 


\section{Discussion: Strategies to Increase Retention Rates}

Our findings from the regression models suggest that California CSA farmers can influence retention rates with some specific strategies, discussed below. But first we discuss some caveats. As we used regional variables as control variables, the model assumes geographical homogeneity about how most of these strategies can work; however, whether these strategies will work for specific CSAs is an open question due to the substantial variation between CSAs, and the increased levels of competition that CSAs face from non-CSAs. The model also assumes that these characteristics are the factors shaping retention rates, rather than being proxies for other factors (e.g., it could be that all CSAs with a large diversity of crop types are better at record keeping which improves the quality of their customer service, which could be an underlying, unaccounted-for variable not captured in the model). Another important caveat is that we have not determined whether the extra effort required to implement any suggested strategy is worth the resulting increase in retention rate, since doing so would involve very complex valuation procedures outside of the scope of this analysis. As production conditions are different in each CSA, each operator will need to weigh whether to attempt any or all strategies based on their potential benefit within their operation.

As for the model's strengths, it is based upon rigorously-tested statistical relationships from a relatively large sample and a very large dataset of hundreds of variables. As such, we likely captured real relationships between retention rates and CSA characteristics that farmers can change through management decisions. Thus, based on the consistently significant variables in Table 8 , we suggest that CSAs can pursue the strategies below to increase retention rates. In the following suggestions, we note the relevance of the size of the coefficient and how it relates to increased retention rates:

1. Make their shares available for a longer duration, since each additional month corresponds to a $2.8 \%$ increase in retention rate.

2. Increase the diversity of their crop types by growing fruit, nuts, grains and pulses, and/or flowers, since each additional crop type increases retention by $5 \%$;

3. Include fruit in their standard shares, since including the farm's fruit in standard shares increases retention rate by $8.6 \%$;

4. Bring their farming practices into line with organic standards, since not doing so corresponds to a $31 \%$ reduction in retention rate;

5. Work together with other nearby CSAs to reduce inter-CSA competition, since a higher perceived competition index decreases retention (as the index ranges from 0 to 2, a 1-point increase corresponds to an $11 \%$ lower retention rate); and

6. Change or expand marketing region to regions with less competition, since selling in the North Coast, Delta/East Bay, and South Coast regions results in a $17 \%$ to $23 \%$ reduction in retention rates.

While we framed all but one of these strategies for implementation by individual CSAs, collaborating directly with other CSAs can allow farmers to implement strategies 1, 3, and 6 above, and is crucial to strategy 5 . Increasing inter-CSA collaboration, such as coordinating share production through cooperative or collaborative CSAs, can reduce competition between CSAs in the same region by allowing more specialization by each farm, thereby reducing the logistical complexities of farming dozens of crop types. The benefits could also include sharing marketing efforts, customer and delivery logistics, and the use of farm equipment [9]. In California, we heard from CSA operators who recommend other CSAs when their members move to a new community, and in instances where their box option is not the right fit for the member's family. There were also instances of CSA farmers and managers expanding their product offerings by working with producers to source products that did not grow well on their own farm or products that they were not interested in producing. More broadly, regional CSA coordinating networks (e.g., FairShare CSA Coalition in Madison, Wisconsin, USA and Équiterre in Quebec, Canada) take the concept further and allow the network to centralize the process of CSA sign-ups, produce delivery to drop-off locations, outreach and educational efforts, and other 
services. FairShare has been in operation for over 20 years, and it coordinates education, outreach, community building, and resource sharing amongst CSAs in Southern Wisconsin [33]. They organize an annual open house, where attendees can learn more about CSAs in their community, meet farmers, and sign-up for shares. In theory, such networks should reduce inter-CSA competition, thereby allowing for greater retention.

There is also the beginning of building a network of already-existing regional CSA networks in the USA. In 2018, FairShare and the Community Alliance for Family Farmers, a non-profit organization based in California, were awarded a United States Department of Agriculture (USDA) Farmers Market Promotion grant to improve resource sharing and training amongst CSAs. This kind of increased collaboration is a key element to making the CSA model work better and reducing CSA farmer self-exploitation [7], and may go a long way towards reducing the burden of member recruitment and education on any one CSA operation.

\section{Conclusions}

Our analysis points toward specific strategies that CSA farmers and managers can use to increase retention rates. The analysis has proceeded from a very different starting place than most other analyses about CSA retention, which have focused almost entirely on former members and the reasons why they left (e.g., [12]). The literature on former members suggests that getting the product mix more in line with former members' wants would increase retention rates; however, Galt et al. [11] and our analysis above demonstrate that share customization has no effect on retention rates. Galt et al. ([11] p. 10) call this the "CSA customization paradox" and suggest that, while former members note that they want more choice within the share, they "actually want more choice for non-seasonal produce," which CSAs cannot address while staying true to the model of ecologically-based, local-farm provisioning. Thus, we suggest that the method of attempting to increase retention rates by listening to and pleasing former members is barking up the wrong tree.

Not only is increasing customizability unlikely to increase retention rates, but it may actually reinforce values among members and potential members that undermine the CSA model and potentially negatively impact member retention in the long run [34]. These values include the focus on individual benefits over the collective good and the consideration of price over other product attributes (e.g., positive social and environmental impacts). The CSA model emerged with the understanding of the transformational potential of sharing in the expenses, risks, and benefits of sustainable agriculture. There are positive correlations between member satisfaction (as evidenced by retention above), collective management practices (including a core group of members and members forming a supportive community around the farm), and farmer wellbeing. Indeed, CSAs as originally conceived need to engage in a transformation of their members from being driven by their own economic self-interests to taking into greater consideration the civil and collective benefits [34-38].

Member education, done collectively as discussed above, may productively extend beyond annual open houses and into the realm of developing collective values and shared community economies. As noted in the previous section, in the USA there is already a movement to enhance support of inter-CSA collaborative practices; this includes an informal California CSA Network, a "national CSA Community of Practice" supported by USDA funding [39], and the efforts of service-providing firms like Small Farm Central. These and other similar movements and platforms have the potential to assist over-worked CSA farmers by providing educational materials to members and potential members (e.g., written and video recipes and information about agroecology) that help cultivate "CSA people" [11] and sharing best practices that demonstrate the social and economic benefits of deepening member-farmer relations and collaboration between CSA operations.

Thus, through this analysis we have identified another tree to bark up: By analyzing the retention rates of 80 CSAs and correlating specific characteristics to retention rates, we attempted to identify what is working and not working for CSA member retention in California. The analysis identifies strategies which would not have been identified by asking former members, even large-scale studies 
that take multiple CSA's members into account [11]. As engaged and activist scholars, we are interested in hearing from CSAs that attempt to implement these or other strategies as ways to retain more members, and whether they work or not. This can help to inform future studies that could update or contradict the findings here and/or examine retention relationships in other regions.

Author Contributions: R.E.G. oversaw the project and conceptualized the analysis. R.E.G., K.M.-D., and K.B. curated the dataset used. R.E.G. produced the original draft of the manuscript and all authors contributed to the analysis, writing, and editing. L.O.C. and R.E.G. responded to reviewer comments and made manuscript revisions for acceptance.

Funding: This research was funded by a competitive grant Galt received from University of California's Division of Agriculture and Natural Resources. The APC was jointly funded by Galt's position as MacArthur Foundation Endowed Chair in Global Conservation and Sustainable Development and from Van Soelen Kim's ANR Program Support funding.

Conflicts of Interest: The authors declare no conflict of interest.

\section{References}

1. Lyson, T.A. Civic Agriculture: Reconnecting Farm, Food, and Community; Tufts University Press: Medford, MA, USA, 2004.

2. Galt, R.E.; Beckett, J.; Hiner, C.C.; O'Sullivan, L. Community Supported Agriculture (CSA) in and around California's Central Valley: Farm and Farmer Characteristics, Farm-Member Relationships, Economic Viability, Information Sources, and Emerging Issues; University of California: Davis, CA, USA, 2011.

3. Schoolman, E. Local, Local on the Wall... Are CSAs the "Greenest" of Them All? In Proceedings of the Annual Meeting of the Agriculture, Food, and Human Values Society, Madison, WI, USA, 13-16 June 2018.

4. Galt, R.E. Counting and mapping community supported agriculture in the United States and California: Contributions from critical cartography/GIS. ACME Int. E J. Crit. Geogr. 2011, 10, 131-162.

5. Galt, R.E.; O'Sullivan, L.; Beckett, J.; Hiner, C.C. Community Supported Agriculture is thriving in the Central Valley. Calif. Agric. 2012, 66, 8-14. [CrossRef]

6. Lass, D.; Bevis, A.; Stevenson, G.W.; Hendrickson, J.; Ruhf, K. Community Supported Agriculture Entering the 21st Century: Results from the 2001 National Survey; University of Massachusetts, Department of Resource Economics: Amherst, MA, USA, 2003.

7. Galt, R.E. The moral economy is a double-edged sword: Explaining farmers' earnings and self-exploitation in Community Supported Agriculture. Econ. Geogr. 2013, 89, 341-365. [CrossRef]

8. Sneddon, C.S. 'Sustainability' in ecological economics, ecology and livelihoods: A review. Prog. Hum. Geogr. 2000, 24, 521-549. [CrossRef]

9. Galt, R.E.; Bradley, K.; Christensen, L.; Van Soelen Kim, J.; Lobo, R. Eroding the community in community supported agriculture (CSA): Competition's effects in alternative food networks in California. Sociol. Rural. 2016, 56, 491-512. [CrossRef]

10. Huntley, S. CSA, We Have a Problem. Available online: https://www.harvie.farm/blog/csa-we-have-aproblem/ (accessed on 24 July 2017).

11. Galt, R.E.; Bradley, K.; Christensen, L.O.; Munden-Dixon, K. The (un)making of "CSA people": Member retention and the customization paradox in Community Supported Agriculture (CSA) in California. J. Rural Stud. 2019, 65, 172-185.

12. Kane, D.J.; Lohr, L. Maximizing Shareholder Retention in Southeastern CSAs: A Step Toward Long Term Stability; University of Georgia: Athens, Greece, 1997.

13. Goland, C. Community supported agriculture, food consumption patterns, and member commitment. Cult. Agric. 2002, 24, 14-25. [CrossRef]

14. Perez, J.; Allen, P.; Brown, M. Community Supported Agriculture on the Central Coast: The CSA Member Experience; Center for Agroecology and Sustainable Food Systems, University of California: Santa Cruz, CA, USA, 2003.

15. Bregendahl, C.; Flora, C.B. The Role of Collaborative Community Supported Agriculture: Lessons from Iowa; North Central Regional Center for Rural Development: Ames, IA, USA, 2006.

16. Russell, W.S.; Zepeda, L. The adaptive consumer: Shifting attitudes, behavior change and CSA membership renewal. Renew. Agric. Food Syst. 2008, 23, 136-148. [CrossRef] 
17. Feagan, R.; Henderson, A. Devon Acres CSA: Local struggles in a global food system. Agric. Hum. Values 2009, 26, 203-217. [CrossRef]

18. Flora, C.B.; Bregendahl, C. Collaborative community-supported agriculture: Balancing community capitals for producers and consumers. Int. J. Sociol. Agric. Food 2012, 19, 329-346.

19. Zepeda, L.; Reznickova, A.; Russell, W.S. CSA membership and psychological needs fulfillment: An application of self-determination theory. Agric. Hum. Values 2013, 30, 605-614. [CrossRef]

20. Landis, B.; Smith, T.E.; Lairson, M.; McKay, K.; Nelson, H.; O’Briant, J. Community-Supported Agriculture in the Research Triangle Region of North Carolina: Demographics and Effects of Membership on Household Food Supply and Diet. J. Hunger Environ. Nutr. 2010, 5, 70-84. [CrossRef]

21. Lang, K.B. The changing face of Community-Supported Agriculture. Cult. Agric. 2010, 32, 17-26. [CrossRef]

22. Member Assembler. The 2015 CSA Farming Annual Report: Trends and Statistics in CSA Farming; Small Farm Central: Pittsburgh, PA, USA, 2016; Available online: http://www.memberassembler.com/hub/csa-report (accessed on 12 July 2017).

23. Member Assembler. The 2014 CSA Farming Annual Report: Trends and Statistics in CSA Farming; Small Farm Central: Pittsburgh, PA, USA, 2015; Available online: https://s3.amazonaws.com/StaticSFCFiles/2014_CSA_ Farming_Report.pdf (accessed on 12 July 2017).

24. Docter, M.; Hildebrand, L. CSA success depends on retention; here's how to keep members happy. Grow. Mark. 1998, 7, 4-6.

25. Lang, K.B. Expanding our understanding of Community Supported Agriculture (CSA): An examination of member satisfaction. J. Sustain. Agric. 2005, 26, 61-79. [CrossRef]

26. Tegtmeier, E.; Duffy, M. Community Supported Agriculture (CSA) in the Midwest United States: A Regional Characterization; Leopold Center, Iowa State University: Ames, IA, USA, 2005.

27. Guthman, J. Agrarian Dreams: The Paradox of Organic Farming in California; University of California Press: Berkeley, CA, USA, 2004.

28. Cone, C.A.; Kakaliouras, A. Community supported agriculture: Building moral community or an alternative consumer choice. Cult. Agric. 1995, 15, 28-31. [CrossRef]

29. Groh, T.; McFadden, S. Farms of Tomorrow: Community Supported Farms, Farm Supported Communities; Bio-dynamic Farming and Gardening Association: Kimberton, PA, USA, 1990.

30. Henderson, E.; Van En, R. Sharing the Harvest: A Citizen's Guide to Community Supported Agriculture, rev. expanded ed.; Chelsea Green: White River Junction, VT, USA, 2007.

31. Filan, T.R. Invisible Farmers, Invisible Farms: Gender and Agriculture in Two Northern California Counties; University of California: Davis, CA, USA, 2011.

32. Bowens, N. The Color of Food: Stories of Race, Resilience and Farming; New Society Publishers: Gabriola Island, BC, Canada, 2015.

33. FairShare CSA Coalition. About FairShare CSA Coalition. Available online: https://www.csacoalition.org/ about-us/ (accessed on 2 April 2019).

34. DeLind, L.B. Close encounters with a CSA: The reflections of a bruised and somewhat wiser anthropologist. Agric. Hum. Values 1999, 16, 3-9.

35. Lamb, G. Community supported agriculture: Can it become the basis for a new associative economy? Threefold Rev. 1994, 11, 39-43.

36. Lamb, G. Going beyond self-interest in economic life, part I: Rudolf Steiner's indications on the ownership and use of land and other means of production. Threefold Rev. 1996, 13, 17-26.

37. Lamb, G. Overcoming self interest in social life: Part II-Rudolf Steiner's indications on economic associations. The Threefold Review 1997, 15, 6-18.

38. Gibson-Graham, J.K. A Postcapitalist Politics; University of Minnesota Press: Minneapolis, MN, USA, 2006.

39. Community Alliance with Family Farmers. Community Supported Agriculture (CSA). Available online: https://www.caff.org/programs/ftm/csas/ (accessed on 2 April 2019).

(C) 2019 by the authors. Licensee MDPI, Basel, Switzerland. This article is an open access article distributed under the terms and conditions of the Creative Commons Attribution (CC BY) license (http://creativecommons.org/licenses/by/4.0/). 